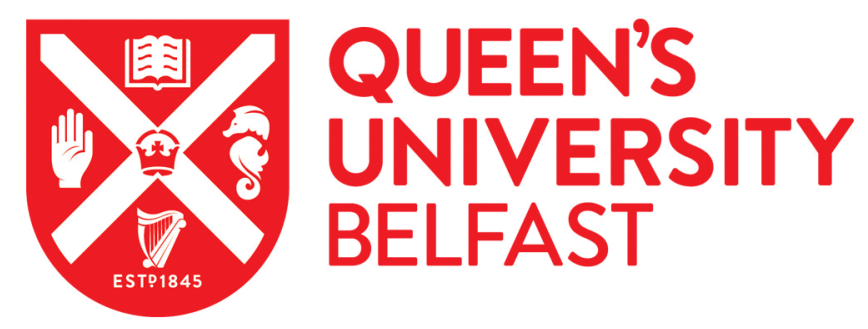

\title{
Evaluation of rumen temperature as a novel indicator of meat quality: Rumen temperature and haematological indicators of stress during the pre-slaughter period as predictors of instrumental meat quality in bulls.
}

Rutherford, N., Lively, F., \& Arnott, G. (2019). Evaluation of rumen temperature as a novel indicator of meat quality: Rumen temperature and haematological indicators of stress during the pre-slaughter period as predictors of instrumental meat quality in bulls. Meat Science. https://doi.org/10.1016/j.meatsci.2019.107913

Published in:

Meat Science

Document Version:

Peer reviewed version

Queen's University Belfast - Research Portal:

Link to publication record in Queen's University Belfast Research Portal

\section{Publisher rights}

Copyright 2019 Elsevier.

This manuscript is distributed under a Creative Commons Attribution-NonCommercial-NoDerivs License

(https://creativecommons.org/licenses/by-nc-nd/4.0/), which permits distribution and reproduction for non-commercial purposes, provided the author and source are cited.

\section{General rights}

Copyright for the publications made accessible via the Queen's University Belfast Research Portal is retained by the author(s) and / or other copyright owners and it is a condition of accessing these publications that users recognise and abide by the legal requirements associated with these rights.

Take down policy

The Research Portal is Queen's institutional repository that provides access to Queen's research output. Every effort has been made to ensure that content in the Research Portal does not infringe any person's rights, or applicable UK laws. If you discover content in the Research Portal that you believe breaches copyright or violates any law, please contact openaccess@qub.ac.uk. 
Evaluation of rumen temperature as a novel indicator of meat quality: Rumen temperature and haematological indicators of stress during the pre-slaughter period as predictors of instrumental meat quality in bulls

6

\section{$7 \quad$ Author names and affiliations}

8

Naomi Heather Rutherford ${ }^{1,2}$, Francis Owen Lively ${ }^{1}$, Gareth Arnott ${ }^{2}$

9

${ }^{1}$ Agri-Food and Biosciences Institute, Hillsborough, Co. Down, Northern Ireland, BT16 6DR

${ }^{2}$ School of Biological Sciences, Queen's University Belfast, Belfast, Northern Ireland

Corresponding author

Naomi Heather Rutherford 
The use of new technologies such as rumen temperature boluses, together with the collective assessment of an animal stress responses may have the potential to act as an indicator of meat quality. Therefore, the objective of this study was to evaluate rumen temperature as a novel indicator of meat quality, by investigating its relationship with welfare measures and instrumental meat quality. The study involved 42 Holstein bulls ( $15.8 \pm 0.08$ months of age), which were transported $42 \mathrm{~km}$ to a commercial abattoir. Mean rumen temperature rose by $0.511^{\circ} \mathrm{C}(P<0.001)$ during the pre-slaughter phase; peaking during lairage. In addition, cortisol, creatine kinase (CK) and lactate dehydrogenase $(\mathrm{LDH})$ were significantly $(P<0.001)$ elevated at slaughter. Bulls with a greater rumen temperature during the pre-slaughter phase produced meat with significantly higher $\mathrm{pH}_{\text {ult. }}$ Pre-slaughter rumen temperature was positively associated with slaughter CK, slaughter cortisol, $\mathrm{pH}_{\mathrm{ult},} L^{*}$ and $a^{*}$. Thus, rumen temperature demonstrates the potential to be used both as a novel welfare indicator and predictor of meat quality.

Keywords: rumen temperature bolus; stress-induced hyperthermia; ultimate $\mathrm{pH}$; cortisol; creatine kinase

\subsection{Introduction}

Cattle are subject to a number of stressful situations; including transportation, social mixing and exposure to novel environments and personnel in the pre-slaughter period of their life (Ferguson \& Warner, 2008; Miranda-de la Lama, Villarroel, \& Marıa, 2014). This period which consists of all events from loading at the farm until slaughter at the abattoir represents a risk to both animal welfare and meat quality (Hemsworth et al., 2011; Lomiwes, Farouk, Wu, \& Young, 2014) which results in a significant cost for the red meat industry (Teke, Akdag, Ekiz, \& Ugurlu, 2014). Suboptimal 
meat quality is primarily caused by accelerated glycogenolysis during the pre-slaughter period. This process is initiated by the release of catecholamines following the activation of the sympathetic nervous system and is aimed at generating energy required for the initiation of a stress response (Ponnampalam et al., 2017). As a result meat quality is compromised due to insufficient acidification post-slaughter, which leads to a high ultimate $\mathrm{pH}$ ( $\mathrm{pH}_{\text {ult }}$ (Tarrant \& Lacourt, 1984). Muscle activity, injury and fatigue can also be associated with a stress response, and will further add to the negative impact on meat quality. The occurrence of such muscular damage can be detected by the presence of muscle enzymes in serum such as creatine kinase (CK) and lactate dehydrogenase (LDH) (LosadaEspinosa, Villarroel, Maria, \& Miranda-de la Lama, 2018).

Other haematological measures of a stress response are often used as welfare indicators; with the stress hormone cortisol being commonly used (Cafazzo et al., 2012). Cortisol is secreted in response to the release of adrenocorticotrophic hormone (ACTH) (Shaw \& Tume, 1992); with changes in serum concentration being detectable minutes after exposure to a stressor, and lasting for up to two hours (Trunkfield \& Broom, 1990).

Stress-induced hyperthermia is a well-documented physiological response to stressful events (Bouwknecht, Olivier, \& Paylor, 2007; Losada-Espinosa et al., 2018; Pascual-Alonso et al., 2017; Pedernera-Romano, Ruiz de la Torre, Badiella, \& Manteca, 2011). Hyperthermia occurs when the thermoregulatory system is altered by the autonomic nervous system; causing the thermoregulatory set point to be increased (Spooren, Schoeffter, Gasparini, Kuhn, \& Gentsch, 2002). Rumen temperature boluses are a new technology primarily marketed for the detection of ill health, and they enable non-invasive, continuous data collection (Timsit, Assié, Quiniou, Seegers, \& Bareille, 2011). Therefore, their use may assist with providing broader insights into stress-induced hyperthermia in cattle, particularly with regard to the effects of the handling, journey and lairage during the pre-slaughter period; an area where their application has so far been overlooked. 
Thus, an observational study was conducted to determine associations between instrumental meat quality and the pre-slaughter phase rumen temperature and existing physiological welfare measures. Specifically, we examine the hypothesis that changes in rumen temperature will be associated with behavioural, haematological and meat quality indicators.

\subsection{Materials and methods}

This study was undertaken in June 2018 at the Agri-Food and Biosciences Institute (AFBI), Hillsborough, Northern Ireland. AFBI is located at latitudes and longitudes of $54.45^{\circ}$ and $-6.07^{\circ}$, respectively and is $91 \mathrm{~m}$ above sea level. The area has a mean annual temperature of $8.6^{\circ} \mathrm{C}$ and a mean annual rainfall of $1024 \mathrm{~mm}$ (Climate Data, 2019). Mean temperature for June 2018 was $15.1^{\circ} \mathrm{C}$ (MetOffice, 2018). All experimental procedures used in this study were conducted in compliance with the United Kingdom Animals (Scientific Procedures) Act 1986.

\subsubsection{Animal management and experimental design}

A total of 42 Holstein bulls, $15.8 \pm 0.08$ months of age and $575.9 \pm 8.84 \mathrm{~kg}$ live weight were used in this study. Bulls were selected as they represent $10 \%$ of the prime cattle slaughtered in the UK, and are widely known to be more susceptible to stress than steers or heifers (Bonny et al., 2016; Tennessen, Price, \& Berg, 1983). Bulls were housed indoors on slatted accommodation and split between 13 pens in groups of one $(n=1)$, two $(n=8)$, three $(n=21)$ or four $(n=12)$ bulls. Bulls were offered grass silage and concentrates ad libitum for 240 days prior to the commencement of this study, the chemical composition of these feeds is shown in Table 1. Bulls were transported to a commercial abattoir in a double decker lorry with passive ventilation, at a space allowance of $1.53 \mathrm{~m}^{2}$. The journey which was primarily along a dual-carriageway was $42 \mathrm{~km}$; with a journey time of $46 \mathrm{~min}$. The lorry was subdivided into 8 pens and bulls were transported in a groups of four $(n=8)$, five $(n=15)$, six $(n=12)$ or seven $(n=7)$. Prior to unloading at the abattoir bulls had a stationary waiting time of $38 \mathrm{~min}$. Bulls were all unloaded into one pen, and thus mixing occurred during lairage. Mean time spent in lairage was $86.9 \mathrm{~min}$, and ranged from 56 to $117 \mathrm{~min}$. The bulls were slaughtered using 

stage of this study, nor was electrical stimulation during processing.

Table 1: Chemical composition of feed

\begin{tabular}{lcc}
\hline Chemical composition & Grass silage & Concentrates \\
\hline $\mathrm{DM}\left(\mathrm{g} \mathrm{kg}^{-1}\right)$ & 272 & 866 \\
$\mathrm{CP}\left(\mathrm{g} \mathrm{kgDM}^{-1}\right)$ & 124 & 150 \\
$\mathrm{ME}(\mathrm{MJ} \mathrm{kgDM}-1)$ & 10.6 & 11.1 \\
$\mathrm{ADF}\left(\mathrm{g} \mathrm{kgDM}^{-1}\right)$ & 313 & 121 \\
$\mathrm{NDF}\left(\mathrm{g} \mathrm{kgDM}^{-1}\right)$ & 532 & 295 \\
Ash $\left(\mathrm{g} \mathrm{kgDM}^{-1}\right)$ & 106 & 82.4 \\
Nitrogen $\left(\mathrm{g} \mathrm{kgDM}^{-1}\right)$ & 14.7 & 28.7 \\
\hline
\end{tabular}

98

\subsubsection{Environmental conditions}

Farm conditions were recorded using a weather station (Davis Vantage Pro 2, Davis Instruments,

USA) positioned externally in central point of the farm. Environmental conditions during transport were recorded using two iButtons (Hydrochron, DS1923 F5, Maxim Integrated, USA) which were secured to the sides of the lorry just above animal height; ensuring the face of the iButton was not obscured. In both cases ambient temperature $\left({ }^{\circ} \mathrm{C}\right)$ and relative humidity $(\mathrm{RH} \%)$ were recorded and used to calculate the temperature-humidity index (THI) for the farm and during transport. THI was calculated using the formula below where $\mathrm{T}$ is ambient temperature $\left({ }^{\circ} \mathrm{C}\right)$ and $\mathrm{RH}$ is relative humidity expressed as a proportion (Hahn, Gaughan, Mader, \& Eigenberg, 2009)

$$
T H I=0.8 T+R H(T-14.4)+46.4
$$

\subsubsection{Rumen temperature}

Rumen temperature $\left({ }^{\circ} \mathrm{C}\right)$ was automatically recorded at five minute intervals, using a rumen temperature bolus (ThermoBolus Small, Medria, France). The dimensions of the cylindrical bolus were $7 \times 2.5 \mathrm{~cm}$, with a weight of $64.6 \mathrm{~g}$. The factory-calibrated bolus recorded to a tenth of a degree Celsius. Each bull had a rumen temperature bolus administered from three months of age; animals 
were restrained in a head locking crush and boluses were administered orally using an applicator.

Prior to transport, data was downloaded from the boluses continually, however once the bulls were loaded, the boluses were out of range for data download to occur. Thus, boluses were recovered from the rumen following slaughter and brought back to AFBI to allow the remaining data to be downloaded. A basal rumen temperature was established for each bull during the $48 \mathrm{~h}$ prior to loading. Rumen temperature during transportation and lairage were comprised of the durations between loading and unloading; and between unloading and slaughter, respectively. For each of the three phases, a mean and maximum rumen temperature were calculated.

\subsubsection{Blood collection and live weight} (T2) and at slaughter (T3). T1 and T2 were obtained via tail venipuncture at approximately the same time each morning; with the mean of these considered as an individual basal value. Bulls were also weighed full (due to an ad libitum diet) on both occasions using walk over scales; with the mean being considered as the slaughter weight. $\mathrm{T3}$ was taken from the jugular vein during exsanguination at a mean of $249.2 \pm 3.96 \mathrm{~min}(4 \mathrm{~h} 9 \mathrm{~min})$ after T2. Blood $(10 \mathrm{ml})$ was collected into evacuated tubes (with no additive) at each time point for determination of cortisol, CK and LDH. Blood samples were stored at $4^{\circ} \mathrm{C}$ until centrifuged.

\subsubsection{Observations}

Stock person actions toward each animal were recorded during $\mathrm{T} 1, \mathrm{~T} 2$ and at loading; in addition animal behaviour was also scored during loading. On each occasion bulls were identified by a number (1-42) which was spray painted across the animals back, this number was then crossreferenced with the bulls registered identification number. Ethograms and scoring systems (Table 2 and 3) were adapted from Hultgren et al. (2014); these ethograms were designed for use in a driving

137 race at an abattoir and thus, minor alterations were made to each ethogram for application to this study. The observation period for T1 and T2 occurred for the full duration the animal was outside its 
pen. A total of two trained stockpersons were present and scored; the first brought animals to and from the weigh area, the second moved the animals through the weigh area. Actions of the two stockpersons were combined at each time point to give scores for the full observational period. Two stockpersons were also present during loading, and the observational period was recorded using a GoPro Camera (Hero 5 Session), and videos later scored using The Observer XT13 software. rating for animal behaviour (AWR BEH) for each animal.

Table 2: Stockperson actions during handling and loading (adapted from Hultgren et al., 2014)

\begin{tabular}{llc}
\hline \multicolumn{1}{c}{ Action } & \multicolumn{1}{c}{ Description } & $\begin{array}{c}\text { Animal Welfare } \\
\text { rating }\end{array}$ \\
\hline Speaking & Speaks or whistles softly and quietly & 0 \\
Shouting & Speaks or shouts harshly or loudly & 2 \\
Rattling & Makes noise by shakes rattle or clapping hands & 1 \\
Slamming & Makes noise by hitting wall with a tool & 1 \\
Touching rear & Touches the animal behind hip bone with hand & 1 \\
Touching front & Touches the animal in front of hip bone with hand & 1 \\
Slapping rear & Slaps the animal behind hip bone with hand & 2 \\
Slapping front & Slaps the animal in front of hip bone with hand & 2 \\
Touching rear -tool & Touches the animal behind hip bone with tool & 1 \\
Touching front -tool & Touches the animal in front of hip bone with tool & 2 \\
Hitting rear -tool & Hits the animal behind hip bone with tool & 3 \\
Hitting front -tool & HIts the animal in front of hip bone with tool & 3 \\
Booting & Kicks the animal & 3 \\
Gate hitting & Closes gate on animal & 2 \\
Tail twisting & Bends or twists tail & 3 \\
Any other action & Any other action & -
\end{tabular}

Table 3: Animal behaviours during loading (adapted from Hultgren et al., 2014) 


\begin{tabular}{llc}
\multicolumn{1}{c}{ Behaviour } & \multicolumn{1}{c}{ Description } & $\begin{array}{c}\text { Animal Welfare } \\
\text { rating }\end{array}$ \\
\hline Crowding & $\begin{array}{l}\text { Is prevented by other animals from moving forwards } \\
\text { or backwards }\end{array}$ & 2 \\
Moving forwards & Moves at least 2 steps forwards \\
Moving backwards & Moves at least 2 steps backwards & 0 \\
Turning & Turns or attempts to turn & 2 \\
Running & Runs forward & 2 \\
Jumps onto lorry & Jumps onto ramp of lorry & 2 \\
Minor slipping & Feet slide, but continues to walk forward & 0 \\
Major slipping & Feet slide and stops walking, but only hooves or legs & 1 \\
Falling & in contact with floor & 2 \\
Kicking & Body in contact with floor & \\
Minor struggling & Kicks legs behind towards stockperson & Repeatedly trips, moves from side to side or kicks \\
Major struggling & Repeatedly throws itself against wall, jumps, tosses & 2 \\
Freezing & head, shivers or pants & 2 \\
Vocalising & Stops moving and refuses to walk despite repeated & 3 \\
Exploring & attempts by stockperson & 2 \\
Any other behaviour & Makes vocal sounds & Looks around or sniffs surrounding while standing still \\
& Any other action & 2 \\
\end{tabular}

\subsubsection{Haematological variables}

Blood samples were centrifuged at $3,000 \mathrm{rpm}$ at $4^{\circ} \mathrm{C}$ for $20 \mathrm{~min}$. Plasma was collected from each sample and stored at $-20^{\circ} \mathrm{C}$ until analysis was conducted by NationWide Laboratories (England). Cortisol concentration was determined using an Immulite 2000 analyser (Siemens Healthcare Diagnostics Inc.,Belmont, CA) with a solid-phase competitive chemiluminescent enzyme immunoassay. The mean interassay CV $(n=20)$ was $5.0 \%$ for cortisol. CK and LDH were measured using a clinical chemistry analyser (Model AU640; Beckman Coulter, UK). For CK the mean intraassay CV $(n=20)$ was $1.14 \%$ and the interassay CV $(n=20)$ was $2.43 \%$. Similarly, for LDH the mean intraassay CV $(n=20)$ was $1.13 \%$ and the interassay CV $(n=20)$ was $1.52 \%$.

\subsubsection{Instrumental meat quality}

At slaughter, carcass weight, fat classification and carcass conformation were recorded according to the EU classification system. At $24 \mathrm{~h}$ post-slaughter, carcass sides were split between the $9^{\text {th }}$ and $10^{\text {th }}$ 
rib, and the longissimus dorsi muscle was scored for marbling using the United States Department of Agriculture scoring system (Agricultural Research Council, 1965). Subcutaneous fat depth (mm) was also measured at three points; $1 / 4,1 / 2$ and $3 / 4$ along the length of the longissimus dorsi muscle on both sides of the carcass, the mean of these values was taken as the subcutaneous fat depth for each animal (Kirkland, Patterson, Keady, Moss, \& Steen, 2007).

One meat sample (mean weight $0.93 \pm 0.028 \mathrm{~kg}$ ) from the longissimus dorsi muscle was removed from the fore-rib joint at 4 days post-slaughter. The meat sample was then split evenly into two samples which were aged at $3^{\circ} \mathrm{C}$, one until D7 and the other until D14 post-slaughter. At D7 $\mathrm{pH}_{\text {ult }}$ was assessed using a Jenway $370 \mathrm{pH}$ meter (Jenway, UK) and calibrated prior to measurements being taken using two buffer solutions of $\mathrm{pH} 4$ and $\mathrm{pH} 7$. Colour (L*(lightness), $\mathrm{a}^{*}($ redness) and $\mathrm{b}^{*}$ (yellowness)) was also assessed on D7 using a Jenway $370 \mathrm{pH}$ meter (Jenway, UK) which was calibrated using a white tile. D7 and D14 samples were then vacuum-packed and blast froze, where they were stored for two months until further measurements were taken.

Samples were left to thaw over a period of $24 \mathrm{~h}$ at $4{ }^{\circ} \mathrm{C}$. Following this, they were removed from the packaging and left to bloom for $40 \mathrm{~min}$. D7 and D14 samples were scored for marbling using the MSA scoring system (MLA, 2006); with the mean of D7 and D14 considered as the marbling score. Samples were vacuum-packed and cooked in a water bath at $70^{\circ} \mathrm{C}$ for $50 \mathrm{~min}$. Samples were weighed pre- and post-cooking, and cooking loss was calculated as follows:

$$
\text { Cooking loss } \%=\left(\frac{\text { pre cooking weight }- \text { post cooking weight }}{\text { pre cooking weight }}\right) 100
$$
Instron 3366 Universal Testing Instrument. Samples were cored parallel to the longitudinal orientation of the muscle fibres and 10 cores (sub-samples) were taken from each meat sample. All 
fibres. The mean maximum load of the 10 sub-samples was considered as the WBSF value for each meat sample.

\subsubsection{Statistical Analysis}

191

All statistical analysis were completed using Genstat ( $16^{\text {th }}$ edition). Summary statistics were conducted on carcass characteristics and animal welfare scores. Analysis of rumen temperature and haematological variables were carried out using linear mixed models with repeated measures. Animal was fitted as the subject factor and time point as a fixed effect. The correlation between time points was accounted for using an antedependence model of order 1 . A series of one way ANOVAs with Fishers Protected LSD were used to examine the effect of $\mathrm{pH}_{\text {ult }}$ group on a range of measures including; rumen temperature, haematological variables, behavioural measures and meat quality. The models identifying factors associated with rumen temperature were developed using a stepwise multiple regression analysis, with both forward and backward selection methodologies employed. Explanatory variables included haematological variables (cortisol, CK and LDH) at slaughter (T3), and instrumental meat quality characteristics ( $\mathrm{pH}_{\mathrm{ult}}, \mathrm{L}^{*}, \mathrm{a}^{*}, \mathrm{~b}^{*}$, cooking loss and WBSF); combinations of these variables were compared to identify the best model. This model was then fitted to a multiple linear regression, and evaluated on the basis of residual variance. The models developed to predict meat quality characteristics were developed using the same methodology, however in this case the explanatory variables included haematological variables (cortisol, CK and LDH) at slaughter (T3), and rumen temperature.

\subsection{Results}

Two rumen temperature boluses were unable to be recovered at the abattoir and thus final temperature data was not obtained for these bulls. As a result, they were removed from the study; and the results presented below are for 40 bulls. 
Mean ambient temperature and relative humidity $( \pm S E M)$ on the farm during the 24 hour period $\pm 0.654 \%$, subsequently, giving a mean THI of $64.13 \pm 0.222$.

\subsubsection{Observations}

216 The mean of the animal welfare ratings derived from stock person actions during T1, T2 and loading,

217 are shown in Table 4. Loading had the greatest mean animal welfare rating of 56.59, the mean number of times an animal was hit during loading was 4.2. This measure included four actions from the ethogram in Table 2; touches rear with tool, touches front with tool, hitting rear with tool and hitting front with tool. Mean animal welfare rating based on behaviour was 3.78; there were no incidences of falling, kicking or struggling during loading.

Table 4: Summary statistics of animal welfare ratings and hitting counts

\begin{tabular}{|c|c|c|c|c|}
\hline & Mean & SEM & Median & Maximum \\
\hline AWACT T1 ${ }^{a}$ & 8.95 & 1.552 & 6.5 & 40.0 \\
\hline AWACT T2 ${ }^{a}$ & 4.53 & 1.151 & 2.0 & 29.0 \\
\hline AWACT Loading ${ }^{a}$ & 56.59 & 9.055 & 29.8 & 229.5 \\
\hline Count of hitting during loading $b$ & 4.20 & 1.283 & 0.0 & 36.0 \\
\hline AWBEH Loading $^{c}$ & 3.78 & 0.498 & 4.0 & 12.0 \\
\hline \multicolumn{5}{|c|}{$\begin{array}{l}\text { a Sum of animal welfare rating per animal deriv } \\
\text { b Count of hitting using a "tool" during loading } \\
{ }^{c} \text { Sum of animal welfare scores per animal deriv }\end{array}$} \\
\hline
\end{tabular}




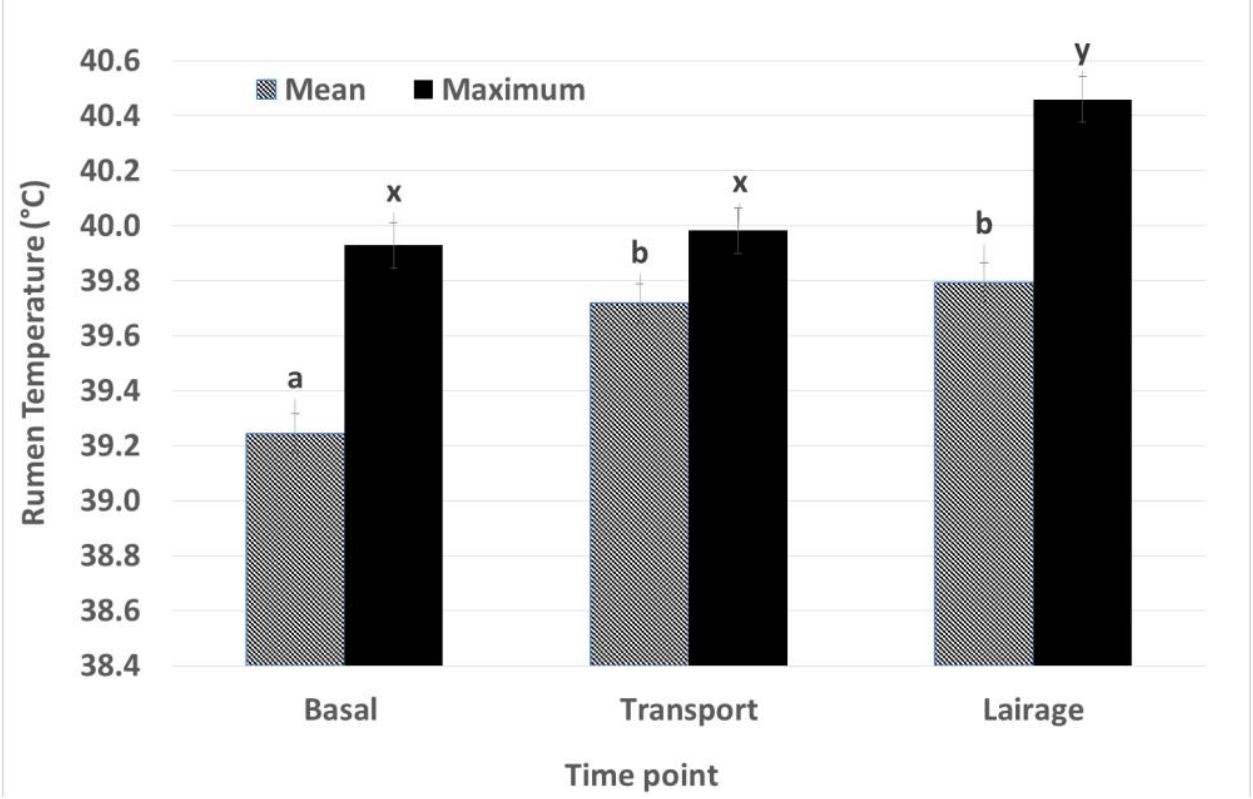

Basal: 48 hour period prior to loading; Transport: loading to unloading; Lairage: unloading to slaughter; $a, b$ represent significant differences $(P<0.001)$ between mean temperatures; $x$, y represent significant differences $(P<0.001)$ between maximum temperatures.

Figure 1: Rumen temperature $\left({ }^{\circ} \mathrm{C}\right)$ at three time points

228 Rumen temperature (Figure 1$)$ increased significantly $(P<0.001)$ during the pre-slaughter phase.

229 Mean temperature increased by $0.511^{\circ} \mathrm{C}$, while maximum temperature increased by $0.568^{\circ} \mathrm{C}$.

230 Although mean rumen temperature was not significantly different during transport or lairage;

231 maximum rumen temperature was significantly greater $(P<0.001)$ during lairage $\left(40.46 \pm 0.085^{\circ} \mathrm{C}\right)$;

232 with $90 \%$ of bulls reaching their peak rumen temperature during this time.

\subsubsection{Haematological variables}

234 The effect of the pre-slaughter phase on haematological variables is presented in Table 5. Cortisol,

235 CK and LDH were all significantly elevated $(P<0.001)$ at slaughter. Haematological variables did not 236 differ $(P>0.05)$ between T1 and T2.

Table 5: Haematological variables of bulls at three timepoints

\begin{tabular}{lccccccc}
\hline & T1 & T2 & T3 & SED & F & dof & Sig. \\
\hline Cortisol (nmol/l) & $33.7^{a}$ & $34.1^{a}$ & $68.6^{b}$ & 4.33 & 19.83 & $2 / 47.5$ & $<0.001$ \\
CK (ui/l) & $363^{a}$ & $204^{a}$ & $900^{b}$ & 124.4 & 30.82 & $2 / 44.0$ & $<0.001$
\end{tabular}




\begin{tabular}{|c|}
\hline DH (ui/l) \\
\hline
\end{tabular}

T1: $24 \mathrm{~h}$ prior to transport; T2: $0 \mathrm{~h}$ prior to transport; T3: Slaughter. CK: creatine kinase; LDH: lactate dehydrogenase; $a, b$ represent significant differences between timepoints.

\subsubsection{Carcass characteristics and meat quality}

Table 6 outlines the carcass characteristics of the bulls used in this study. Carcass characteristics were not associated with rumen temperature, haematological variables or instrumental meat quality, and thus these relationships are not documented.

Table 6: Summary statistics of carcass characteristics

\begin{tabular}{|c|c|c|}
\hline & Mean & SEM \\
\hline Slaughter age (days) & 479.6 & 2.24 \\
\hline Slaughter LW (kg) & 576.0 & 8.73 \\
\hline Carcass weight (kg) & 294.1 & 5.48 \\
\hline Carcass conformation $^{a}$ & 4.35 & 0.141 \\
\hline Carcass fat classification ${ }^{b}$ & 7.05 & 0.232 \\
\hline Subcutaneous fat depth (mm) & 6.47 & 0.277 \\
\hline Marbling (USDA) ${ }^{c}$ & 2.05 & 0.121 \\
\hline $\begin{array}{l}\text { aScore 1-15 (1=P-, 15=E+) } \\
\text { bScore 1-15 (1= 1-, 15=5+) } \\
\text { cScore 1-8 (1= A (Traces), 8=H }\end{array}$ & & \\
\hline
\end{tabular}

When $\mathrm{pH}_{\text {ult }}$ is considered within three thresholds $(<5.8 ; 5.8-6.2 ;>6.2)$ (Chulayo, Bradley, \& Muchenje, 2016; Jeremiah, Tong, \& Gibson, 1991) a clear difference is observed between rumen temperature values. Table 7 illustrates that bulls with a meat $\mathrm{pH}>6.2$ had the greatest mean rumen temperature $\left(40.13^{\circ} \mathrm{C}\right)$ during the pre-slaughter phase $(P<0.001)$, in addition there was a tendency for mean rumen temperature to be increased when $\mathrm{pH}_{\text {ult }}$ was $5.8-6.2$ in comparison to those $<5.8$. Maximum rumen temperature during the pre-slaughter phase was significantly different $(P<0.001)$ within each of the three $\mathrm{pH}_{\mathrm{ult}}$ ranges. There were no significant differences $(P>0.05)$ in the duration that rumen temperature was elevated above the individual basal level between the three $\mathrm{pH}$ categories. In contrast, time spent above $40^{\circ} \mathrm{C}$ was significantly greater $(\mathrm{P}<0.001)$ for bulls with a $\mathrm{pH}_{\text {ult }}>6.2$. 
Stockperson actions, animal behaviour during loading and lairage duration did not differ $(P>0.05)$

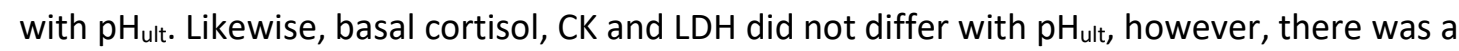

There were no significant differences $(P>0.05)$ in carcass characteristics between the three $\mathrm{pH}_{\text {ult }}$

ranges and thus these results are not shown in Table 7. Greater values for meat colour $\left(L^{*}(P<0.01)\right.$,

$\left.a^{*}, b^{*}(P<0.001)\right)$ were observed for meat with a $\mathrm{pH}_{\text {ult }}<5.8$. Cooking loss and WBSF were the lowest for a $\mathrm{pH}_{\text {ult }}$ range of 5.8-6.2, the difference was not significant from that at a $\mathrm{pH}_{\text {ult }}<5.8$.

\subsubsection{Relationship between rumen temperature, haematological variables and instrumental meat}

quality

Table 8 outlines the post-slaughter factors that were related to pre-slaughter phase rumen greatest $\mathrm{R}^{2}$ value of 52.5 and included three variables: $a^{*}, \mathrm{CK}$ at slaughter and $\mathrm{pH}_{\text {ult. }}$ Mean rumen

Table 7: Rumen temperature, behavioural measures, haematological variables and instrumental meat quality according to ultimate $\mathrm{pH}$

\begin{tabular}{|c|c|c|c|c|c|c|}
\hline & \multicolumn{3}{|c|}{ Ultimate $\mathrm{pH}$} & \multirow[b]{2}{*}{ SED } & \multirow[b]{2}{*}{$\mathbf{F}$} & \multirow[b]{2}{*}{ Sig. } \\
\hline & $<5.8$ & $5.8-6.2$ & $>6.2$ & & & \\
\hline Number of bulls $(n)$ & 19 & 11 & 10 & & & \\
\hline Basal RT $\left({ }^{\circ} \mathrm{C}\right)$ & 39.24 & 39.24 & 39.26 & 0.079 & 0.07 & ns \\
\hline Mean RT during transport $\left({ }^{\circ} \mathrm{C}\right)$ & $39.65^{a}$ & $39.64^{\mathrm{a}}$ & $39.94^{b}$ & 0.103 & 5.13 & $<0.05$ \\
\hline Mean $\mathrm{RT}$ during lairage $\left({ }^{\circ} \mathrm{C}\right)$ & $39.55^{a}$ & $39.63^{a}$ & $40.43^{b}$ & 0.262 & 6.46 & $<0.01$ \\
\hline Maximum RT during basal period $\left({ }^{\circ} \mathrm{C}\right)$ & $39.83^{a}$ & $39.80^{a}$ & $40.25^{b}$ & 0.143 & 5.64 & $<0.01$ \\
\hline Maximum $\mathrm{RT}$ during transport $\left({ }^{\circ} \mathrm{C}\right)$ & $39.87^{\mathrm{a}}$ & $39.90^{a}$ & $40.28^{b}$ & 0.132 & 5.49 & $<0.01$ \\
\hline Maximum RT during lairage $\left({ }^{\circ} \mathrm{C}\right)$ & $40.06^{a}$ & $40.52^{b}$ & $41.16^{c}$ & 0.194 & 17.33 & $<0.001$ \\
\hline Time RT > Basal (min) & 190.0 & 175.0 & 185.0 & 11.64 & 0.99 & ns \\
\hline Time $\mathrm{RT}>40^{\circ} \mathrm{C}(\mathrm{min})$ & $47.1^{\mathrm{a}}$ & $58.2^{a}$ & $125.0^{b}$ & 19.76 & 8.64 & $<0.001$ \\
\hline AWACT T1 & 6.8 & 7.1 & 15.0 & 3.78 & 2.76 & ns \\
\hline
\end{tabular}




\begin{tabular}{|c|c|c|c|c|c|c|}
\hline AWACT T2 & 4.9 & 3.3 & 5.3 & 2.99 & 0.23 & ns \\
\hline AWACT Loading & 52 & 57 & 65 & 23.5 & 0.18 & ns \\
\hline Count of stockman hitting (Loading) & 4 & 4 & 5 & 3.3 & 0.09 & ns \\
\hline AWBEH Loading & 4 & 3 & 4 & 1.3 & 1.19 & ns \\
\hline Lairage duration (min) & 93 & 54 & 79 & 7.5 & 1.93 & ns \\
\hline Basal Cortisol (nmol/l) & 32.3 & 33.5 & 37.4 & 2.87 & 0.84 & ns \\
\hline Basal CK (ui/l) & 161 & 162 & 653 & 239.0 & 2.56 & ns \\
\hline Basal LDH (ui/l) & 3073 & 3076 & 3276 & 229.6 & 0.47 & ns \\
\hline Slaughter Cortisol (T3) (nmol/l) & 62.1 & 76.5 & 72.1 & 14.2 & 0.65 & ns \\
\hline Slaughter CK (T3) (ui/l) & $559^{a}$ & $982^{b}$ & $1458^{c}$ & 211.0 & 9.79 & $<0.001$ \\
\hline Slaughter LDH (T3) (ui/I) & 3596 & 3829 & 3949 & 214.2 & 1.62 & ns \\
\hline L* (Lightness) & $39.56^{b}$ & $36.53^{a}$ & $35.86^{a}$ & 1.160 & 6.88 & $<0.01$ \\
\hline$a^{*}$ (redness) & $27.04^{c}$ & $23.60^{b}$ & $22.27^{\mathrm{a}}$ & 0.569 & 43.6 & $<0.001$ \\
\hline b* (blue/yellow) & $10.56^{c}$ & $8.22^{b}$ & $6.98^{a}$ & 0.497 & 30.6 & $<0.001$ \\
\hline Marbling Score (MSA) & 718 & 682 & 722 & 50.1 & 0.37 & ns \\
\hline Cooking loss D7 (\%) & $26.05^{c}$ & $23.63^{b}$ & $19.58^{a}$ & 0.737 & 40.9 & $<0.001$ \\
\hline Cooking loss D14 (\%) & $25.68^{b}$ & $24.99^{b}$ & $19.43^{a}$ & 1.381 & 12.1 & $<0.001$ \\
\hline WBSF D7 (kg) & $4.70^{b}$ & $5.18^{\mathrm{b}}$ & $3.43^{a}$ & 0.341 & 17.1 & $<0.001$ \\
\hline WBSF D14 (kg) & $4.46^{\mathrm{b}}$ & $4.71^{\mathrm{b}}$ & $2.96^{\mathrm{a}}$ & 0.266 & 22.1 & $<0.001$ \\
\hline
\end{tabular}

RT: Rumen temperature; AWACT: Sum of animal welfare scores per animal derived from stockperson actions; AWBEH: Sum of animal welfare scores per animal derived from animal behaviour; a,b,c represent significant differences between Ultimate $\mathrm{pH}$ threshold $n d f=2, d d f=37 ; n=40$

269 temperature during transport was associated with CK at slaughter, while that during lairage was

270 associated with CK and cortisol at slaughter. The model identified for maximum rumen temperature

271 consisted of two meat quality parameters: $\mathrm{pH}_{\mathrm{ult}}$ and $L^{*}$.

272 Table 9 outlines the combination of haematological variables and rumen temperature

273 measurements that can be used as predictors of meat quality. The greatest $R^{2}$ value (53.1) was

274 observed for $\mathrm{pH}_{\text {ult }}$ with a combination of maximum lairage rumen temperature, $\mathrm{CK}$ and cortisol at

275 slaughter being used as predictor variables. Maximum rumen temperature during lairage and CK at

276 slaughter was the most common model for predicting meat quality; being used for three measures

$277 \quad L^{*}, a^{*}$ and cooking loss D7. 
Table 8: Post-slaughter factors associated with rumen temperature

\begin{tabular}{|c|c|c|c|c|c|c|c|c|c|c|c|c|c|c|}
\hline $\mathbf{Y}$ & Model $\left(X_{1}+X_{2}+X_{3}\right)$ & intercept & s.e. & t pr. & $X_{1}$ & s.e. & t pr. & $X_{2}$ & s.e. & t pr. & $X_{3}$ & s.e. & t pr. & $\mathbf{R}^{2}$ \\
\hline Mean Transport RT & $\mathrm{T} 3 \mathrm{CK}$ & 39.52 & 0.0685 & $<0.001$ & 0.00023 & $6.3 \mathrm{E}-05$ & $<0.001$ & & & & & & & 23.4 \\
\hline Mean Lairage RT & T3CK + T3Cort & 39.81 & 0.241 & $<0.001$ & 0.00061 & 0.00016 & $<0.001$ & -0.0081 & 0.0028 & 0.006 & & & & 32.9 \\
\hline Maximum Transport RT & $\mathrm{pH}_{\mathrm{ult}}+L^{*}$ & 35.78 & 1.44 & $<0.001$ & 0.544 & 0.157 & 0.001 & 0.0247 & 0.0186 & 0.193 & & & & 21.9 \\
\hline Maximum Lairage RT & $a^{*}+\mathrm{T} 3 \mathrm{CK}+\mathrm{pH}_{\mathrm{ult}}$ & 39.69 & 2.99 & $<0.001$ & -0.0883 & 0.0501 & 0.087 & 0.0002 & 0.00015 & 0.133 & 0.467 & 0.335 & 0.172 & 52.5 \\
\hline Time $\mathrm{RT}>40^{\circ} \mathrm{C}$ & $\mathrm{T} 3 \mathrm{CK}+\mathrm{pH}_{\mathrm{ult}}$ & -209.0 & 133.0 & 0.124 & 0.0396 & 0.0147 & 0.011 & 41.2 & 23.8 & 0.092 & & & & 38.0 \\
\hline
\end{tabular}

279

280

281

Table 9: Prediction of meat quality based on rumen temperature and post-slaughter haematological variables

\begin{tabular}{|c|c|c|c|c|c|c|c|c|c|c|c|c|c|c|}
\hline $\mathbf{Y}$ & Model $\left(X_{1}+X_{2}+X_{3}\right)$ & intercept & s.e. & t pr. & $X_{1}$ & s.e. & t pr. & $x_{2}$ & s.e. & t pr. & $\mathbf{X}_{3}$ & s.e. & t pr. & $\mathbf{R}^{2}$ \\
\hline $\mathrm{pH}_{\text {ult }}$ & MaxLRT + T3Cort + T3CK & -7.69 & 3.39 & 0.029 & 0.330 & 0.084 & $<0.001$ & 0.0016 & 0.00129 & 0.220 & 0.00017 & 8.7E-05 & 1.950 & 53.1 \\
\hline$L^{*}$ & MaxLRT & 120.5 & 30.2 & $<0.001$ & -2.045 & 0.747 & 0.009 & & & & & & & 14.3 \\
\hline$a^{*}$ & MaxLRT + T3CK & 136.9 & 18.4 & $<0.001$ & -2.754 & 0.454 & $<0.001$ & -0.0086 & 0.0085 & 0.320 & & & & 47.2 \\
\hline$b^{*}$ & MaxLRT + T3CK & 67.40 & 17.6 & $<0.001$ & -1.422 & 0.441 & 0.003 & -0.0009 & 0.00046 & 0.048 & & & & 45.4 \\
\hline Cooking Loss D7 & MaxLRT + T3CK & 108.7 & 31.6 & 0.001 & -2.072 & 0.793 & 0.013 & -0.0013 & 0.00082 & 0.128 & & & & 33.4 \\
\hline Cooking Loss D14 & MaxLRT + T3Cort & 112.1 & 41.2 & 0.010 & -2.130 & 1.010 & 0.043 & -0.0286 & 0.019 & 0.141 & & & & 9.2 \\
\hline WBSF D7 & MeanLRT + T3CK & 25.00 & 10.0 & 0.017 & -0.507 & 0.255 & 0.054 & -0.0004 & 0.0003 & 0.203 & & & & 17.5 \\
\hline WBSF D14 & MeanLRT + T3CK & 26.12 & 8.08 & 0.003 & -0.546 & 0.205 & 0.011 & -0.0003 & 0.00024 & 0.300 & & & & 23.2 \\
\hline
\end{tabular}

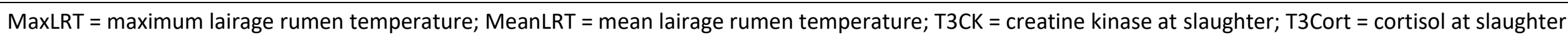




\subsection{Discussion}

283 Consistent with our hypothesis, the results demonstrate that the continuous monitoring of rumen

284

285

286

287

288

289

290

291

292

293

294

295

296

297 temperature during the pre-slaughter phase offers a tool to monitor aspects of animal welfare and meat quality, as evidenced by the relationships between these parameters that were uncovered by the current study.

\subsubsection{Rumen temperature}

Cattle exposed to heat stress will have a greater body temperature and respiration rate (Gaughan \& Mader, 2014). However, in this study mean THI during transportation did not exceed the threshold of 65 outlined by Ammer, Lambertz, and Gauly (2016); above which a rise in rumen temperature can be expected. Thus, the observed rise in rumen temperature was not caused by heat stress. The initiation of a fight or flight response is controlled by the autonomic nervous system (ANS) resulting in a number of physiological changes. These are considered the first line of response upon exposure to a stressful situation, ensued by behavioural changes and the activation of the hypothalamicpituitary-adrenal axis (HPA) (Losada-Espinosa et al., 2018). Thus, the elevated cortisol concentrations at slaughter and associations between rumen temperature and meat quality, indicate that the observed rise in rumen temperature during the pre-slaughter phase was caused by stress-induced hyperthermia.

Mean rumen temperatures during transport and lairage were similar, yet rumen temperature peaked higher during lairage, than in transportation; with bulls having a $0.48^{\circ} \mathrm{C}$ greater maximum temperature during lairage. Bulls had access to water during lairage, and when considering the findings of Bewley, Grott, Einstein, and Schutz (2008), who reported a reduction in rumen temperature associated with water intake; this could be the likely explanation as to why mean rumen temperature did not differ significantly during transport and lairage. However, it should be noted that bulls had access to water during the basal period, and yet mean basal rumen temperature and that of lairage, were significantly different. Thus, indicating that the rise in rumen 
temperature due to stress-induced hyperthermia was substantial enough to supersede any decline caused by water intake.

Furthermore, the rise in rumen temperature during the pre-slaughter period indicates that both transport and lairage were considered novel environments. The progressive habituation of cattle to a novel environment has been well documented (Broom, 2003; Chacon, Garcia-Belenguer, Villarroel, \& Maria, 2005; Njisane \& Muchenje, 2017); with rectal temperatures of bulls peaking within the first 30 min of a 9 hour journey, before recovering to pre-transport levels (Burdick et al., 2010). However, in this study rumen temperature continued to rise throughout the pre-slaughter period, peaking creating a cumulative stressor effect.

One further reason for the elevated temperatures during lairage was that bulls were largely transported within the groups they had been housed in. Whereas, at the abattoir they were all unloaded into one pen and thus, mixing occurred. Social mixing of bulls results in a greater occurrence of aggressive interactions as they attempt to establish a social hierarchy; thus creating social stress (Kenny \& Tarrant, 1987; Tennessen, Pricea, \& Berga, 1985; Warriss, Kestin, Brown, \& Wilkins, 1984). Aggressiveness is also associated with increased physical effort, with possible carcass bruising and muscle damage; the extent of which will largely depend on the intensity and duration of such interactions (Ferguson \& Warner, 2008). Therefore, mixing during lairage would have not only contributed towards the elevated rumen temperatures that were observed in this study; but also is the likely explanation for the elevated CK and LDH concentrations at slaughter (Losada-Espinosa et al., 2018; Tarrant, 1990). This is further supported by the findings shown in Table 8; where rumen temperature during lairage was associated with $a^{*}, \mathrm{CK}$ at slaughter and $\mathrm{pH}_{\text {ult. }}$ In addition Chacon et al. (2005) reported that transport had no effect on CK concentration, provided bulls were 
transported under good conditions; with gentle handling and at recommended stocking densities. Thus, muscle damage associated with transport could well have been minimal in this study.

\subsubsection{Cortisol}

Basal cortisol was in agreement with that of Buckham Sporer, Weber, Burton, Earley, and Crowe (2008); and Chacon et al. (2005), but greater than that observed by Cafazzo et al. (2012), and outlined as reference values by Radostits, Gay, Hinchcliff, and Constable (2007). Cortisol is widely known for its variability (Losada-Espinosa et al., 2018) with concentrations being impacted by numerous animal factors (Grandin, 2000); therefore, irregularity between studies is to be expected. Concentrations of cortisol doubled at slaughter (T3) in comparison to basal levels. Thus, indicating that the pre-slaughter environment was substantially more stressful than the routine handling associated with weighing and blood sampling; which may largely be due to the social mixing and novelty of the pre-slaughter environment (Bourguet, Deiss, Boissy, \& Terlouw, 2015). Chacon et al. (2005) transported bulls for 3 different durations ( $30 \mathrm{~min}, 3 \mathrm{~h} \& 6 \mathrm{~h}$ ); the author observed greater cortisol concentrations for bulls with a journey time of 3 and $6 \mathrm{~h}$ in comparison to basal levels determined one week prior to transportation. Thus, indicating that a short journey ( $30 \mathrm{~min})$ was not substantial enough to activate the hypothalamic-pituitary-adrenocortical axis to the same magnitude as a medium or long journey. Trunkfield and Broom (1990) outlined that a sharp and rapid increase was characteristic of cortisol; with rises occurring within minutes and lasting for up to $2 \mathrm{~h}$. This raises the question as to which part of the pre-slaughter phase was responsible for the rise in cortisol detected in this study. It is possible that the bulk of the observed rise occurred during lairage and hence, cortisol may have followed the same pattern as rumen temperature. However, due to these cattle being slaughtered under commercial conditions, blood sampling post-transport was not practically feasible. Thus, the dynamic pattern of the haematological variables during the pre-slaughter phase of this study is unknown.

\subsubsection{Instrumental meat quality}


The high proportion of carcases with a $\mathrm{pH}_{\text {ult }}>5.8$ are likely due to the individual's perception of the pre-slaughter environment and its associated stressors (Grandin, 1993). The cattle used in this study were naive to transportation, and were all managed within a small stable social group throughout their lifetime. This naivety to the stressors experienced during the pre-slaughter phase may have magnified the individual variability within the group, as individual stress responses were not impacted by previous habituation (Stockman et al., 2011).

Bulls with a $\mathrm{pH}_{\mathrm{ult}}>6.2 \mathrm{had}$ a significantly greater maximum rumen temperature during the basal period; yet there was no difference in mean rumen temperature during this time. Thus, suggesting that these elevations in temperature were acute and hence causes of hyperthermia, such as illhealth could be eliminated (Timsit et al., 2011). Burdick et al. (2010) reported that temperamental bulls had a higher maximum rectal temperature than calm bulls during transportation. Furthermore, research has shown that temperamental or excitable cattle have a greater $\mathrm{pH}_{\text {ult, }}$ and poorer meat quality (Hall et al., 2011; Ponnampalam et al., 2017; Voisinet, Grandin, Oconnor, Tatum, \& Deesing, 1997); due to their increased susceptibility to stress. Therefore, in the current study, an increased maximum basal temperature may indicate that these bulls were more easily raised or stressed, even within an environment in which they were acclimatised to. In addition, the observed relationship between $\mathrm{pH}_{\text {ult }}$ and maximum temperature during both transportation and lairage, further supports this suggestion.

The cattle used in this study, were weighed fortnightly throughout their lifetime and daily feeding was also carried out by a stockperson. Consequently, they were accustomed to regular human interaction; which may be justification as to why stockperson actions had no impact on rumen temperature or meat quality. These findings are supported by previous research which observed a reduction in cortisol response as cattle became habituated to repeated handling (Andrade, Orihuela, Solano, \& Galina, 2001; Solano, Galindo, Orihuela, \& Galina, 2004). Waynert, Stookey, Schwartzkopf- 

over time; with decreased heart rate and movement.

Rumen temperature during the pre-slaughter phase is associated with validated indicators of stress as shown by the models in Table 8. This is as expected, considering that stress results in a number of physiological changes while also initiating glycogenolysis, thus impacting meat quality (Ponnampalam et al., 2017). This demonstrates the potential for rumen temperature, measured using a bolus, to be used to provide broader insights into the welfare of ruminants. Furthermore, rumen temperature may also have the capacity to act as a pre-slaughter indicator of meat quality. When combined with haematological variables at slaughter, particularly CK and Cortisol, models can be identified to define the relationship with instrumental meat quality. This provides valuable information for the red meat industry, which may allow for preventative action to be taken prior to slaughter. Further research would be required to identify the extent to which animal factors (e.g. sex, age, breed) contribute to individual variability; so that a reliable threshold can be identified. In addition, remedial treatments could be evaluated in order to identify the rate at which rumen temperature can be reduced to acceptable levels prior to slaughter. A potential limitation of using rumen temperature boluses, may be the ability for them to be recovered post-slaughter. Although the boluses were easily recovered in this study, the practicalities are largely dependent on the abattoir and economics of recovery. Furthermore, the risk of bolus regurgitation should also be taken into consideration.

\subsection{Conclusion}

In conclusion, bulls had a significantly elevated mean rumen temperature during transport and lairage in comparison to basal levels. Rumen temperature peaked during lairage, possibly due to the cumulative effect of multiple stressors, and social stress associated with mixing during lairage. As a result pre-slaughter rumen temperature was significantly associated with $\mathrm{pH}_{\text {ult. }}$ Cortisol, $\mathrm{CK}$ and LDH were all significantly elevated at slaughter, however, CK was the only haematological variable that 

induced hyperthermia in ruminants, a greater understanding of stress responses can be gained.

Thus, rumen temperature boluses have the potential to be widely used as a welfare indicator and may even have uses as a monitoring tool within animal welfare monitoring schemes. In addition with further research, rumen temperature during the pre-slaughter phase may have the ability to act as a predictor of instrumental meat quality.

\subsection{Acknowledgements}

The authors wish to thank the technical and scientific staff of the Beef Unit and Food Chemistry Department for their assistance with data collection during this study.

\subsection{Funding sources}

This study was jointly funded by the Department of Agriculture, Environment and Rural Affairs for

Northern Ireland and AgriSearchNI.

\subsection{References}

Ammer, S., Lambertz, C., \& Gauly, M. (2016). Is reticular temperature a useful indicator of heat stress in dairy cattle? [Article]. Journal of Dairy Science, 99, 10067-10076. doi: 10.3168/jds.201611282

Andrade, O. A., Orihuela, A., Solano, J., \& Galina, C. S. (2001). Some effects of repeated handling and the use of a mask on stress responses in Zebu cattle during restraint. Applied Animal Behaviour Science 71, 175-181. doi: doi:10.1016/ S0168-1591(00)00177-5

Bewley, J. M., Grott, M. W., Einstein, M. E., \& Schutz, M. M. (2008). Impact of Intake Water Temperatures on Reticular Temperatures of Lactating Dairy Cows. Journal of Dairy Science, 91(10), 3880-3887. doi: https://doi.org/10.3168/ids.2008-1159

Bonny, S. P., Hocquette, J. F., Pethick, D. W., Farmer, L. J., Legrand, I., Wierzbicki, J., . . Gardner, G. E. (2016). The variation in the eating quality of beef from different sexes and breed classes cannot be completely explained by carcass measurements. Animal, 10(6), 987-995. doi: 10.1017/S175173111500292X

Bourguet, C., Deiss, V., Boissy, A., \& Terlouw, E. M. C. (2015). Young Blond d'Aquitaine, Angus and Limousin bulls differ in emotional reactivity: Relationships with animal traits, stress reactions at slaughter and post-mortem muscle metabolism. Applied Animal Behaviour Science, 164, 41-55. doi: https://doi.org/10.1016/j.applanim.2014.12.009

Bouwknecht, J. A., Olivier, B., \& Paylor, R. E. (2007). The stress-induced hyperthermia paradigm as a physiological animal model for anxiety: a review of pharmacological and genetic studies in the mouse. Neurosci Biobehav Rev, 31(1), 41-59. doi: 10.1016/j.neubiorev.2006.02.002

Broom, D. M. (2003). Transport stress in cattle and sheep with details of physiological, ethological and other indicators. [Article]. Deutsche Tierarztliche Wochenschrift, 110(3), 83-+. 
Buckham Sporer, K. R., Weber, P. S. D., Burton, J. L., Earley, B., \& Crowe, M. A. (2008). Transportation of young beef bulls alters circulating physiological parameters that may be effective biomarkers of stress. [Article]. Journal of Animal Science, 86(6), 1325-1334. doi: 10.2527/jas.2007-0762

Burdick, N. C., Carroll, J. A., Hulbert, L. E., Dailey, J. W., Willard, S. T., Vann, R. C., . . Randel, R. D. (2010). Relationships between temperament and transportation with rectal temperature and serum concentrations of cortisol and epinephrine in bulls. Livestock Science, 129(1-3), 166-172. doi: 10.1016/j.livsci.2010.01.020

Cafazzo, S., Magnani, D., Cala, P., Razzuoli, E., Gerardi, G., Bernardini, D., . . Costa, L. N. (2012). Effect of short road journeys on behaviour and some blood variables related to welfare in young bulls. [Article]. Applied Animal Behaviour Science, 139(1-2), 26-34. doi: 10.1016/j.applanim.2012.03.009

Chacon, G., Garcia-Belenguer, S., Villarroel, M., \& Maria, G. A. (2005). Effect of transport stress on physiological responses of male bovines. [Article]. Deutsche Tierarztliche Wochenschrift, 112(12), 465-469.

Chulayo, A. Y., Bradley, G., \& Muchenje, V. (2016). Effects of transport distance, lairage time and stunning efficiency on cortisol, glucose, HSPA1A and how they relate with meat quality in cattle. Meat Sci, 117, 89-96. doi: 10.1016/j.meatsci.2016.03.001

Council, A. R. (1965). Recommended procedures for use in the measurement of beef cattle and carcasses. In A. R. Council (Ed.). London, UK.

Data, C. (2019). Climate Hillsborough Retrieved 06/07/19, from https://en.climatedata.org/europe/united-kingdom/northern-ireland/hillsborough-192038/

Ferguson, D. M., \& Warner, R. D. (2008). Have we underestimated the impact of pre-slaughter stress on meat quality in ruminants? Meat Science, 80(1), 12-19. doi: https://doi.org/10.1016/i.meatsci.2008.05.004

Gaughan, J. B., \& Mader, T. L. (2014). Body temperature and respiratory dynamics in un-shaded beef cattle. Int J Biometeorol, 58(7), 1443-1450. doi: 10.1007/s00484-013-0746-8

Grandin, T. (1993). Behavioral agitation during handling of cattle is persistent over time. Applied Animal Behavior Science, 36, 1-9.

Grandin, T. (2000). Livestock handling and transport (2nd Edition ed.). Oxon, UK: CABI Publishing.

Hahn, G. L., Gaughan, J. B., Mader, T. L., \& Eigenberg, R. A. (2009). Thermal Indices and Their Applications for Livestock Environments. In J. A. DeShazer (Ed.), Livestock Energetics and Thermal Environmental Management American Society of Agricultural and Biological Engineer (pp. 113-130). St. Joseph, MI, USA.

Hall, N. L., Buchanan, D. S., Anderson, V. L., Ilse, B. R., Carlin, K. R., \& Berg, E. P. (2011). Working chute behavior of feedlot cattle can be an indication of cattle temperament and beef carcass composition and quality. [Article]. Meat Science, 89(1), 52-57. doi: 10.1016/j.meatsci.2011.03.020

Hemsworth, P. H., Rice, M., Karlen, M. G., Calleja, L., Barnett, J. L., Nash, J., \& Coleman, G. J. (2011). Human-animal interactions at abattoirs: Relationships between handling and animal stress in sheep and cattle. Applied Animal Behaviour Science, 135(1), 24-33. doi: https://doi.org/10.1016/i.applanim.2011.09.007

Hultgren, J., Wiberg, S., Berg, C., Cvek, K., \& Lunner Kolstrup, C. (2014). Cattle behaviours and stockperson actions related to impaired animal welfare at Swedish slaughter plants. Applied Animal Behaviour Science, 152, 23-37. doi: https://doi.org/10.1016/j.applanim.2013.12.005

Jeremiah, L. E., Tong, A. K. W., \& Gibson, L. L. (1991). THE USEFULNESS OF MUSCLE COLOR AND PH FOR SEGREGATING BEEF CARCASSES INTO TENDERNESS GROUPS. [Article]. Meat Science, 30(2), 97-114. doi: 10.1016/0309-1740(91)90001-7

Kenny, F., \& Tarrant, P. V. (1987). The behavior of young Freisian bulls during social re-grouping at an abattoir. Influence of an overhead electrified wire grid. Applied Animal Behavior Science, 18, 233. 
Kirkland, R. M., Patterson, D. C., Keady, T. W. J., Moss, B. W., \& Steen, R. W. J. (2007). Beef production potential of Norwegian Red and Holstein-Friesian bulls slaughtered at two ages. [Article]. Animal, 1(10), 1506-1514. doi: 10.1017/s1751731107000791

Lomiwes, D., Farouk, M. M., Wu, G., \& Young, O. A. (2014). The development of meat tenderness is likely to be compartmentalised by ultimate $\mathrm{pH}$. Meat Science, 96(1), 646-651. doi: https://doi.org/10.1016/i.meatsci.2013.08.022

Losada-Espinosa, N., Villarroel, M., Maria, G. A., \& Miranda-de la Lama, G. C. (2018). Pre-slaughter cattle welfare indicators for use in commercial abattoirs with voluntary monitoring systems: A systematic review. [Review]. Meat Science, 138, 34-48. doi: 10.1016/j.meatsci.2017.12.004

MetOffice. (2018). UK Climate Summary - June 2018 Retrieved 06/07/19, from https://www.metoffice.gov.uk/binaries/content/assets/metofficegovuk/pdf/weather/learnabout/uk-past-events/summaries/uk monthly climate summary 201806.pdf

Miranda-de la Lama, G. C., Villarroel, M., \& Marı, G. A. (2014). Livestock transport from the perspective of the pre-slaughter logistic chain: a review. Meat Sci, 98, 9-20.

MLA. (2006). Module 6: Meat Standards Australia Grading. version 5.0. Meat \& Livestock Australia. Sydney.

Njisane, Y. Z., \& Muchenje, V. (2017). Farm to abattoir conditions, animal factors and their subsequent effects on cattle behavioural responses and beef quality - A review. [Review]. Asian-Australasian Journal of Animal Sciences, 30(6), 755-764. doi: 10.5713/ajas.16.0037

Pascual-Alonso, M., Miranda-de la Lama, G. C., Aguayo-Ulloa, L., Villarroel, M., Mitchell, M., \& Maria, G. A. (2017). Thermophysiological, haematological, biochemical and behavioural stress responses of sheep transported on road. J Anim Physiol Anim Nutr (Berl), 101(3), 541-551. doi: 10.1111/jpn.12455

Pedernera-Romano, C., Ruiz de la Torre, J. L., Badiella, L., \& Manteca, X. (2011). Associations between open-field behaviour and stress-induced hyperthermia in two breeds of sheep. Animal Welfare, 20, 339-349.

Ponnampalam, E. N., Hopkins, D. L., Bruce, H., Li, D., Baldi, G., \& El-din Bekhit, A. (2017). Causes and Contributing Factors to "Dark Cutting" Meat: Current Trends and Future Directions: A Review. [Review]. Comprehensive Reviews in Food Science and Food Safety, 16(3), 400-430. doi: 10.1111/1541-4337.12258

Radostits, O. M., Gay, C. C., Hinchcliff, K. W., \& Constable, P. D. (2007). Veterinary Medicine - A Textbook of the Diseases of Cattle, Horses, Sheep, Pigs and Goats. (10th ed. ed.). New York, NY: Saunders Elsevier.

Shaw, F. D., \& Tume, R. K. (1992). THE ASSESSMENT OF PRE-SLAUGHTER AND SLAUGHTER TREATMENTS OF LIVESTOCK BY MEASUREMENT OF PLASMA CONSTITUENTS - A REVIEW OF RECENT WORK. [Article]. Meat Science, 32(3), 311-329. doi: 10.1016/0309-1740(92)90095-I

Solano, J., Galindo, F., Orihuela, A., \& Galina, C. S. (2004). The effect of social rank on the physiological response during repeated stressful handling in Zebu cattle (Bos indicus). Physiology \& Behavior, 82(4), 679-683. doi: https://doi.org/10.1016/i.physbeh.2004.06.005

Spooren, W. P. J. M., Schoeffter, P., Gasparini, F., Kuhn, R., \& Gentsch, C. (2002). Pharmacological and endocrinological characterisation of stress-induced hyperthermia in singly housed mice using classical and candidate anxiolytics. European Journal of Pharmacology, 435, 161-170. doi: 10.1016/S0014-2999(01)01562-X

Stockman, C. A., Collins, T., Barnes, A. L., Miller, D., Wickham, S. L., Beatty, D. T., . . Fleming, P. A. (2011). Qualitative behavioural assessment and quantitative physiological measurement of cattle naive and habituated to road transport. [Article]. Animal Production Science, 51(3), 240-249. doi: 10.1071/an10122

Tarrant, P. V. (1990). TRANSPORTATION OF CATTLE BY ROAD. [Article]. Applied Animal Behaviour Science, 28(1-2), 153-170. doi: 10.1016/0168-1591(90)90051-e

Tarrant, P. V., \& Lacourt, A. (1984). Effect of glucocorticoid, insulin and glucose treatment on glycogen content in young bulls. British Veterinary Journal, 140, 337-345. 
Teke, B., Akdag, F., Ekiz, B., \& Ugurlu, M. (2014). Effects of different lairage times after long distance transportation on carcass and meat quality characteristics of Hungarian Simmental bulls. [Article]. Meat Science, 96(1), 224-229. doi: 10.1016/j.meatsci.2013.07.009

Tennessen, T., Price, M. A., \& Berg, R. T. (1983). Bulls vs. steers. III. Effect of time of mixing on darkcutting Feeders Day Report, 63, 27-28.

Tennessen, T., Pricea, M. A., \& Berga, R. T. (1985). The social interactions of young bulls and steers after re-grouping Applied Animal Behaviour Science, 14, 37-47.

Timsit, E., Assié, S., Quiniou, R., Seegers, H., \& Bareille, N. (2011). Early detection of bovine respiratory disease in young bulls using reticulo-rumen temperature boluses. The Veterinary Journal, 190(1), 136-142. doi: http://doi.org/10.1016/j.tvjl.2010.09.012

Trunkfield, H. R., \& Broom, D. M. (1990). Welfare of calves during handling and transport. Applied Animal Behaviour Science, 28, 135-152.

Voisinet, B. D., Grandin, T., Oconnor, S. F., Tatum, J. D., \& Deesing, M. J. (1997). Bos indicus cross feedlot cattle with excitable temperaments have tougher meat and a higher incidence of borderline dark cutters. [Article]. Meat Science, 46(4), 367-377. doi: 10.1016/s03091740(97)00031-4

Warriss, P. D., Kestin, S. C., Brown, S. N., \& Wilkins, L. J. (1984). The time required for recovery from mixing stress in young bulls and the prevention of dark cutting beef. Meat Science, 10, 5368.

Waynert, D. F., Stookey, J. M., Schwartzkopf-Genswein, K. S., Watts, J. M., \& Waltz, C. S. (1999). The response of beef cattle to noise during handling. Applied Animal Behaviour Science, 62(1), 27-42. doi: https://doi.org/10.1016/S0168-1591(98)00211-1 